* Doutor em Filosofia da Educação pela Universidade de São Paulo (USP). Professor permanente do Programa de Mestrado em Direito Negocial da Universidade Estadual de Londrina (UEL). E-mail: biancozgarcia@gmail.com

** Mestre pelo Programa de Mestrado da Universidade Estadual de Londrina - UEL. Mestrado em Direito Negocial, Área de Pesquisa: Direito Processual Civil. Professor do Curso de Direito da Faculdade de Direito de Alta Floresta, Mato Grosso. E-mail: depaulaadvogado@gmail.com

\section{Varas Agrárias - mecanismo de efetivação do acesso à justiça}

\section{Agricultural Courts - effective mechanism OF ACCESS TO JUSTICE}

\author{
Bianco Zalmora Garcia * \\ Roberto de Paula **
}

Resumo: Considera o processo histórico e a legislação agrária que consolidaram o nascimento do latifúndio no Brasil e as resistências populares emergentes dos conflitos pela posse da terra. Propõe a possibilidade de resolução dos conflitos coletivos pela posse da terra e situação de exclusão do trabalhador rural com a criação e instalação da Justiça Agrária. Descreve o fundamento jurídico de tal justiça especializada como decorrente de princípios inseridos na Constituição Federal. Concebe a questão agrária, o acesso à terra e a legitimidade da reivindicação dos Movimentos Sociais Campesinos sob a óptica da efetivação dos fundamentos da República Federativa do Brasil: cidadania, dignidade da pessoa humana. Conclui que somente com uma Justiça Agrária é que se efetivará o princípio constitucional da função social da propriedade, corrigindo distorções que acirram ânimos, provocam conflitos e obstruem a Reforma Agrária.

Palavras-chave: Direito Agrário. Justiça Agrária, Conflitos, Movimentos Sociais.

Abstract: Considers the historical process and agrarian legislation that consolidated the birth of the landlordism in Brazil and popular resistance emerging from conflict over land ownership. Proposes the possibility of resolving collective disputes over land ownership and exclusion situation of rural workers with the creation and installation of Agrarian Justice. Describes the legal basis for such a specialized justice as a consequence of principles included in the Federal Constitution. Conceives the agrarian question, access to land and legitimacy of the claim of Social Movements Rural of Works from the viewpoint of realization of the fundamentals of the Federative Republic of Brazil: citizenship, dignity of the human person. Concludes that only one Agrarian Justice become effective is that the constitutional principle of the social function of property, correcting distortions that fierce ideals, cause conflicts and obstruct Agrarian Reform.

Keywords: Law Agrarian, Agrariam Justice, Conflicts, Social Movements. 


\section{INTRODUÇÃO}

Indiscutivelmente a temática agrária está na pauta da realidade brasileira. Diariamente abordada de maneira superficial desde os noticiários filtrados e ideológicos dos meios de comunicação de massa até nas mesas de discussão das universidades, com pretensão revestida de cientificidade. Os temas ora abordados despertam paixões discursivas acerca das questões agrárias, tais como, direito de propriedade ou direito à propriedade; papel eqüidistante ou juiz agrarista, capaz de se envolver na dramática realidade de conflito coletivo pela posse da terra, entre outras.

Vislumbra-se, ainda que em sede de utopia ( $u$, possibilidade; topos lugar), a possibilidade de resolução dos conflitos coletivos pela posse da terra e da histórica situação de exclusão do trabalhador rural é vislumbrada com a instituição da Justiça Agrária. O fundamento jurídico para tal justiça especializada decorre dos princípios insertos na Constituição Federal e seu suporte acadêmico científico é dado pelo Direito Agrário. Os fundamentos de validade dos ditames constitucionais (princípios) devem se sobrepor ao direito de propriedade privada da terra.

A Questão Agrária é tratada como ferida aberta no tecido social brasileiro. Neste sentido, aborda-se, aqui, não só o chão histórico acerca da cristalização do direito de propriedade e de apropriação da terra, mas também da produção legislativa agrária no processo de formação social, isto é, da atuação e aplicação do Direito, diga-se da aplicação com base na tradição privada ou romana do jus. Assim, sustenta que, com a criação da Justiça Agrária, poderia estabelecer marcos decisionais aceitáveis para apreciação dos conflitos e litígios possessórios coletivos.

O modelo metodológico escolhido é a hermenêutica histórico-dialética. O método histórico-dialético, numa perspectiva sociológica e filosófica é inconteste, pois revela que a temática apreciada se dá no chão da história brasileira e aclara as contradições entre classes e atores sociais envolvidos no contexto. Com esses instrumentais desvela-se que em relação ao jus agrarismo a produção legislativa e a práxis do Judiciário optou por não fixar marcos eqüidistantes no tratamento das demandas, mutilando a idéia de justiça. 


\section{IMPLICAÇÕES HISTÓRICAS E JURÍDICAS DO CONFLITO PELA POSSE DA TERRA NO BRASIL}

A judicialização da Questão Agrária no Brasil é recente se comparada ao processo de formação do latifúndio e de resistência do campesinato pela posse da terra. Para Celso Furtado "a concentração da propriedade da terra está profundamente enraizada na formação histórica do país" (FURTADO, 1989, p.59). A questão agrária desde sua gênese apresenta distorções sociais e jurídicas que refletem e influenciam o Direito na seara agrária da atualidade. $\mathrm{O}$ que ocorreu no Brasil foi a formação de extensos latifúndios e a segregação entre possuidores e marginalizados do acesso a terra.

\subsection{A legislação estrangeira e o Direito Nativo: esta terra tinha dono}

A historiografia oficial é uma visão parcial dos vencedores, não reconhece a existência de um Direito pátrio das nações indígenas no período anterior à colonização (MARÉS, 1989, p.8). No entanto, há que se inferir certo tipo de organização da vida social indígena com sua forma de procedimento no que concerne à propriedade, família, matrimônio, sucessão, delito.

É cediço que, de um modo muito particular, as nações indígenas tinham seu próprio modo de resolver os conflitos sociais e os temas atinentes à vida social. Aclara-se a existência de um Direito Natural (jusnaturalismo), originalmente pátrio, fundado nos mores (costumes) da nação. Alguns autores, dentre eles Jacques Távora Alfonsin, postulam a tese da existência de um "Direito insurgente, eficaz, não-estatal" (ALFONSIN, 1989, p.20) nas remotas comunidades de indígenas e negros do Brasil colonial.

\subsection{As Sesmarias: começou a concentração da propriedade}

Na perspectiva da "história oficial", a questão fundiária brasileira começa com o nomeado regime de sesmaria, cujas raízes remontam ao ano de 1375 , quando o Rei de Portugal D. Fernando I, criou a Lei de Sesmarias, visando a ocupação de terras abandonadas numa época de profunda crise de abastecimento alimentar no Reino. A Lei determinava que os donos das terras ociosas deveriam lavrá-las ou transferi-las a terceiros capazes de torná-las produtivas. 
Na dominada Terra Brasillis o modus operandi na distribuição das terras é a fonte originária do latifúndio. Ocorre que para se ter direito a uma sesmaria, mister se faz ao candidato que seja de negócios, de posse e capacidade econômica para gerir e administrar o principal meio de produção desse sistema, qual seja, o engenho de açúcar. Assim, simultaneamente, acompanhando os primeiros passos da formação da propriedade, germinavam as sementes do Estado.

\subsection{As sesmarias tornam-se latifúndios}

O latifúndio sesmeiro concebe a terra como efetivo símbolo do bem privado, fonte do poder econômico, social, político e jurídico de reduzido número de pessoas. O latifúndio escravagista é o eixo central da atividade econômica colonial e delimitador de uma sociedade extremamente desigual e de classes definidas: senhores e escravos. Dentre as conseqüências da política agrária sesmeira, destacam-se: o fortalecimento do poder político-econômico do sesmeiro, pela concentração da propriedade da terra; modelo agrícola baseado na prática predatória; formação de extensas propriedades; prevalência da monocultura; a mentalidade latifundista, mantenedora de grandes glebas de terras.

Apesar de paulatino declínio e desuso da Lei de Sesmarias em Portugal, e da realidade totalmente diversa, foi aplicada no Brasil durante três séculos, embora não houvesse aqui terras de lavradio abandonado. Pois, as terras eram ocupadas. A ocupação indígena era evidente, visível, com reconhecimento de fronteiras "demarcadas" entre as nações nativas. Assim, os ditos desbravadores, conquistadores, descobridores, na verdade promoveram invasão de uma terra que tinha dono originário.

\subsection{A Questão Agrária no Império: Regime de posse e Insurgência dos Cabanos}

O sistema sesmarial foi extinto em 17/07/1822 pela Resolução n ${ }^{0}$. 76, confirmada pela provisão de 23/10/1823. A partir desta data passou a vigorar o sistema de posse, cuja regularização definitiva efetivou-se em 18 de setembro de 1850, com a Lei $n^{\circ}$. 601- Lei de Terras, também denominada Lei de Terras e Imigração ou ainda Lei de Terras Devolutas. 
Ressalte-se que com a Constituição Imperial de 1824 ficou definitivamente extinto o instituto da sesmaria. Mas, o Diploma Constitucional do Império não tratou da estruturação fundiária do país, mas garantiu o direito de propriedade no Art. 179, XXII, numa clara manifestação da força e do corporativismo latifundista, que persiste até hoje na política brasileira: "Art. 179: (...) XXII - é garantido o direito de propriedade em toda a sua plenitude $[\ldots] "$.

Denomina-se Regime de Posse o interregno temporal sem lei que regulamentasse a aquisição originária de terras, pois do fim do sistema sesmarial (1822) até o advento da Lei de Terras (1850), têm-se 28 anos de lacuna no tocante à legislação agrária.

Nesse contexto, em 1835, um grupo de camponeses se rebela contra a escravidão e a miséria no Pará. Os cabanos eram negros, mulatos e índios. Todos camponeses sem terra. Empreendem uma marcha revolucionária do campo para a cidade. Tomam a Capital (Belém). Executam o governador e conquistam o poder. No entanto, mal sucedeu que não tinham um projeto político de mudança. O Império fortalece suas tropas e massacra sistematicamente a sublevação popular cabana. Estima-se que $40 \%$ dos habitantes da província foram mortos pelas forças imperiais (VARELA, 1998, p.141).

Para impedir a "ocupação desordenada", nesse contexto, mister se faz agir com repressão e para reprimir é necessária uma norma legal coercitiva. No interstício temporal em que se verificou o regime de posse, à elite agrária, cuja força política e jurídica é incontestável, houve tempo o suficiente para gestar o império da lei: a Lei de Terras de 1850, expressão máxima da produção legislativa durante no Império.

Tanto no regime colonial de sesmarias, quanto no de Independência, nota-se uma efervescência de luta e resistência por parte dos posseiros, indígenas e negros.

\subsection{A legislação Agrária na República e Canudos}

A questão agrária, cuja solução se arrasta desde os primórdios da Colônia, foi tema debatido durante a Primeira Constituinte Brasileira. O grupo hegemônico defendia a plena autonomia dos Estados sobre as terras devolutas, objeto de conflitos. Esse grupo era constituído dos latifundiários e coronéis 
que mantinham verdadeiro poderio nos Estados. Assim, foram gestados os dois instrumentos normativos: a Constituição de 1891 e o Código Civil de 1916, que, diga-se de passagem, perdurou até janeiro de 2003.

Com a República a situação no campo continuou a mesma. Com o escopo de continuar o processo de legitimação da dominação dos senhores da terra, convocou-se a Constituinte de 1890. Canudos dá-se durante a República. Cabe chamar atenção para a prática estatal da deslegitimação e desmobilização da organicidade popular, lançando mão da tática de criminalização das lideranças.

Canudos era um arraial isolado e de difícil acesso encravado no sertão, Norte da Bahia. Na região se instalou a partir de 1893 o beato Antônio Vicente Mendes Maciel, o Antônio Conselheiro. O Conselheiro despertou a ira das autoridades e do clero católico, que consideravam-no uma ameaça ao establishment. Dentre outras acusações figura a de que teria comandado uma queima de editais de cobrança de impostos.

Ao lado da reivindicação política, instala-se o discurso da efervescência religiosa e do descrédito pela República, com a conseqüente desobediência civil. A pregação do líder de Canudos fez tremer a terra nos sertões baianos, não somente pelos dons divinatórios (de premonição e cura), mas, sobretudo, pela capacidade política de articular massas de excluídos, e por sensibilizar o sofrido sertanejo a tomar uma posição de luta e resistência. Apesar dos dados incertos e desencontrados dos historiadores, estima-se que uma grande massa de pobres e maltrapilhos acorreu para Canudos, chegando a uma população de mais de 30 mil pessoas (PANINI, 1990, p.47).

A "cidade livre dos camponeses", como Canudos era conhecida, resistiu a três expedições do exército da República. Porém, sucumbiu na quarta expedição, em 5 de outubro de 1897. Carmela Panini assim escreve: "Desta feita, a cidade é destruída. Grande parte dos camponeses é torturada e exterminada. Alguns se suicidam para não se entregarem ao exército [...]". (PANINI, 1990, p.48).

Canudos é um exemplo de resistência na história campesina brasileira. Resistiu até o esgotamento completo. Euclides da Cunha, na obra Os Sertões, narra quando caíram os seus últimos defensores: "Eram quatro apenas: um velho, dois homens feitos e uma criança, na frente dos quais rugiam raivosamente cinco mil soldados" (CUNHA, 2002, p.532). 


\subsection{O tratamento da Questão Agrária no século XX e o ressurgimento da luta pela terra: as Ligas Agrárias Campesinas}

Um otimismo exagerado marca o início do século XX. O pensamento cientificista se impõe, com a fé cega no razão como instrumento, nas ciências da natureza e no liberalismo como modelo econômico hegemônico.

O Brasil, inserido no contexto mundial, experimenta essas promessas e mudanças da Modernidade. Entretanto, em relação ao jus agrarismo a ação estatal é de manutenção da estrutura agrária preestabelecida. Entre 1940 e 1964 ocorre verdadeira efervescência no campo brasileiro. Fábio Alves do Santos (1995, p.106) destaca os movimentos desencadeados em diferentes regiões do país:

Resistência dos camponeses em Porecatu, norte do Paraná (1950); Revolta de Formoso e Trombas, no norte de Goiás (1954); O sindicalismo dos trabalhadores rurais de Governador Valadares, Minas Gerais (1955); a Resistência do Sudoeste do Paraná, Pato Branco e Francisco Beltrão (1957); Liga Camponesa, em Pernambuco e Paraíba; o Movimento dos Agricultores Sem Terra-MASTER -, nos anos 60, no Rio Grande do Sul.

O nascimento das Ligas Camponesas está intimamente ligada à atuação do Partido Comunista Brasileiro (PCB). No Nordeste, a crise da cana-de-açúcar, no início do século, fez com que os senhores de engenho arrendassem terras a foreiros, passando a viver de rendas provenientes do foro e do cambão. Ocorre que, com a Segunda Guerra, cresce a demanda pelo açúcar e o preço sobe. Assim, levas de foreiros foram expulsos ou obrigados a se sujeitarem a trabalhos forçados nas usinas, sem justa remuneração.

$\mathrm{Na}$ década de 40, os trabalhadores rurais iniciam um processo de organização, sob a orientação do PCB. Em 1948 o Partido é colocado na ilegalidade, desaparece toda organização inicial em torno das Ligas. Em 1954, os foreiros do Engenho Galiléia formam uma associação agrícola e passam a lutar contra as tentativas de expulsão por parte do dono do engenho. A resistência toma dimensão nacional via imprensa. Ressurge a nomenclatura "Liga Camponesa" para o movimento dos "galileus", agora sob a orientação do advogado e deputado socialista pernambucano Francisco Julião. 
As Ligas organizam-se Ligas em treze Estados. Emerge não só a discussão pela Reforma Agrária, mas sob o lema "Reforma Agrária na lei ou na marra" desencadeia-se pela primeira vez a prática de ocupações de terras (ocupação é diferente de invasão, por não cumprir requisitos legais ou de interesses sociais). Tal atitude provoca o recrudescimento e iminente investida do latifúndio (latifundiários).

O contexto histórico da Ligas remonta ao horizonte utópico de implementação da Reforma Agrária. A luta pela terra viveu verdadeiro paradoxo. Em 1963 o Presidente João Goulart (Jango) promulgou o Estatuto do Trabalhador Rural (ETR). Em síntese, o Estatuto não contemplou a expectativa das Ligas Camponesas, que viu neste uma estratégia governamental para controlá-la, cooptá-la, deslegitimando-a em prol de um sindicalismo rural. Caio Navarro de Toledo, assevera que diante do impasse criado, a proposta de Julião foi que as ligas assumissem o protagonismo e a vanguarda política dos sindicatos (TOLEDO, 1986, p.778).

Assim, os movimentos agrários "lançam suspeita das reais intenções do presidente, enquanto os senhores da terra e setores conservadores do empresariado condenam o presidente de ser o causador da agitação e desestabilização nacional" (DREIFUSS, 1981, p.162).

Os historiadores são uníssonos em considerar que o evento do dia 13 de março de 1964, denominado "comício das reformas", que contou com cerca de 200 mil pessoas, foi o estopim para a queda do governo. Ao final do discurso, Jango promulga dois decretos (nacionalização das refinarias de petróleo e desapropriação de 100 hectares que margeiam as rodovias e ferrovias federais). Promete, para breve, enviar ao Congresso Nacional os projetos de reformas de base, entre eles, o da reforma agrária.

Passados quinze dias do comício, instala-se no país o golpe militar. As Ligas e os demais focos de luta pela terra são sistematicamente eliminados.

\subsubsection{Ditadura Militar (1964/1985) e o Estatuto da Terra (Lei nº 4504, de 30 de novembro de 1964)}

O nascimento do Estatuto da Terra remete aos conturbados anos de governo de João Goulart. Em 1962, sob intensa pressão do campesinato, especialmente das Ligas Camponesas, Jango encaminha ao Parlamento proposta do Estatuto da Terra. O projeto tinha fundamento moderado e liberal/burguês, 
mantendo-se nos limites da Constituição de 1946: preservava a intangibilidade da propriedade privada e, a destarte do processo de miséria dos trabalhadores rurais, propunha a facilitação do acesso à terra por meio de créditos aos camponeses. $\mathrm{O}$ escopo declarado era criar uma classe média no meio rural.

Apesar dos fundamentos moderados do projeto, foi rechaçado e, com o golpe de 1964, aprovou-se um novo Estatuto da Terra (Lei $n^{\circ} .4504$, de 30 de novembro de 1964). A retórica era de que o progresso adviria da modernização da produtividade agrícola. Assim, abasteceriam os centros urbanos, atingindo mercados externos e aumentar-se-ia o poder de compra dos camponeses. A proposta era simples: a modernização agrícola como solução do problema agrário. Esse foi o projeto vitorioso da burguesia agrária: o resultado foi o êxodo rural.

A fim de minimizar o grande êxodo rural, os governos do regime militar empreenderam uma verdadeira epopéia de ocupação do território. O corifeu do jus agrarismo brasileiro e ex-procurador do IBRA - Instituto Brasileiro de Reforma Agrária - órgão criado pelo Estatuto da Terra e que depois se transformou no INCRA, Fernando Pereira Sodero, denominou essa investida de ocupação dos "espaços vazios".

Os trabalhadores rurais que migraram do campo para a cidade, especialmente no Sul e Sudeste, eram recrutados em projetos de colonização. Os pequenos proprietários eram seduzidos pela propaganda oficial a venderem suas terras e a adquirir lotes maiores a preços bem abaixo do mercado no norte do país. O slogan oficial "integrar para não entregar”, prestava de suporte ideológico para encaminhar um processo de ocupação e colonização, especialmente da Amazônia.

A Ditadura Militar esmerou-se em conter o avanço das organizações populares tanto no campo como na cidade. A Igreja Católica no Brasil, de início, apoiou o golpe militar. Mas, aos poucos se distancia do regime, tornandose refúgio para lideranças e, por meio de seus agentes, implanta o projeto das Comunidades Eclesiais de Base-CEBs. Nasce dentro dessa experiência a Comissão Pastoral da Terra (CPT), que chega até a organizar ocupações de terras. A CPT é considerada como uma das responsáveis pelo nascimento do Movimento dos Trabalhadores Rurais Sem Terra do Brasil, o MST. Muitas lideranças passaram pela experiência comunitária das CEBs.

Paulatinamente com o enfraquecimento das bases do regime militar dáse o ressurgimento da luta pela terra. O enfrentamento político e ideológico fica 
claro desde o primeiro momento da convocação da Assembléia Nacional Constituinte (Constituição de 1988). A bancada ruralista se organiza em torno da UDR (União Democrática Ruralista) e os parlamentares afins da luta popular expressam a histórica reivindicação de acesso à terra, especialmente colocada na pauta-do-dia pelo MST. Neste contexto, a CF88 agasalha o conceito e princípio da função social da propriedade.

\subsubsection{A Constituição Federal de 1988}

A Constituição da República Federativa do Brasil, promulgada em 05 de outubro de 1988, já no capítulo dos direitos e garantias individuais, assentou que "a propriedade atenderá a sua função social" (art. 5, XXIII) e imanta esse princípio no art. 186, in verbis:

Art. 186. A função social é cumprida quando a propriedade rural atende, simultaneamente, segundo critérios e graus de exigência estabelecidos em lei, aos seguintes requisitos: I - aproveitamento racional e adequado, II utilização adequada dos recursos naturais disponíveis e preservação do meio ambiente; III - observância das disposições que regulam as relações de trabalho;IV - exploração que favoreça o bem-estar dos proprietários e dos trabalhadores.

Com a acolhida constitucional do princípio da função social da propriedade descortina-se para os movimentos sociais a possibilidade de nova hermenêutica constitucional e de judicialização dos conflitos coletivos agrários pela posse da terra, tendo como fundamento os valores de uma Constituição Dirigente que vincula o legislador e o aplicador do Direito.

\section{A CRIAÇÃO DA JUSTIÇA AGRÁRIA E AUTONOMIA DO DIREITO AGRÁRIO}

As matérias afetas à ciência do Direito Agrário são as relações emergentes no mundo agrário, tendo como base a função social da propriedade. Ora, a demanda coletiva pela posse da terra é uma temática emergente, que muitos autores jus agraristas não anteviram. A luta coletiva pela posse da terra atinge níveis de dramaticidade. Assim, não se trata meramente de se inserir na definição do Direito Agrário a reivindicação coletiva dos Movimentos 
Sociais, mas de efetivá-la como expressão garantista de direitos sociais e como realização e salvaguarda da promoção da dignidade humana, erigida a fundamento do Estado Democrático de Direito (CF 88, art.1 ${ }^{\circ}$, III). Nesse passo, a questão agrária e a luta pela terra gozam de legitimidade, porquanto, trata-se de realização do preceito constitucional de promoção da dignidade humana.

O ponto crucial em relação ao Direito Agrário refere-se à autonomia jurisdicional. O problema situa-se com relação à práxis. A autonomia jurisdicional é uma "bandeira de luta" dos jus agraristas comprometidos com a efetivação dos princípios basilares desse ramo do conhecimento jurídico. Trata-se da aplicação dos conceitos e preceitos constitucionais da função social da propriedade como efetivação de direitos fundamentais.

Os conflitos agrários ou fundiários quase sempre acontecem no interior ou nos recônditos sertões do país. Assim, prima facie, as demandas caem necessariamente nas mãos de juízes de Direito de Primeira Entrância, que formados sob a égide civilística, prescindem tanto da normatividade do Texto Constitucional como também da teoria jurídica jus agrarista, cuja natureza e regime jurídico distinguem do ramo privatista.

\subsection{Breves considerações da Proposta de uma Justiça Agrária}

Com a Constituinte de 87, os eminentes agraristas, cônscios da necessidade de uma justiça agrária para o país, intensificaram a luta para ver a sua previsão na Constituição Federal. Vários trabalhos e estudos sobre o assunto foram publicados. O que surgiu da Constituinte foi uma "solução paliativa" a que se refere o dispositivo do artigo 126 inserido na Constituição Federal de 1988, verbis:

Art. 126. Para dirimir conflitos fundiários, o Tribunal de Justiça designará juízes de entrância especial, com competência exclusiva para questões agrárias. Parágrafo único. Sempre que necessário à eficiente prestação jurisdicional, o juiz far-se-á presente no local do litígio (CF88. Art. 126, redação original).

A Emenda Constitucional n ${ }^{\circ} .45$, de 08 de dezembro de 2004, conhecida como Reforma do Judiciário veio alterar, entre outros, o art. 126 da CF/88 que, passou a figurar com a seguinte redação: 
Para dirimir conflitos fundiários, o Tribunal de Justiça proporá a criação de varas especializadas, com competência exclusiva para questões agrárias. Parágrafo único. Sempre que necessário à eficiente prestação jurisdicional, o juiz far-se-à presente no local do litígio (CF88, art. 126).

Salta aos olhos a intenção do legislador em limitar a atuação das varas especializadas a serem criadas "para dirimir conflitos fundiários", atribuindo apenas competência para julgar as ações decorrentes de conflitos fundiários, que correspondem apenas aos conflitos pela posse ou propriedade da terra.

\subsection{Características e idéias de uma Justiça Agrária}

Atém-se aqui a alguns pontos importantes a delinear os contornos de uma Justiça Especializada Agrária, a saber: quais as características de uma Justiça Agrária (?); em que seria diferente dos Tribunais existentes na atualidade (?); qual a teleologia que justifica a criação dessa justiça especializada (?).

\section{3 da necessidade de juiz com "mentalidade agrarista"}

Simbolicamente o imaginário popular é permeado da idéia de que os operadores jurídicos, especialmente os juízes, são inatingíveis, numa espécie de detentores do saber de uma cultura oculta. Em parte essa idéia ou simbologia (WARAT, 2002, p.91) foi incutida pela aplicação individualista e civilista do Direito.

Qual a tarefa que se impõe ao Juiz agrário? Qual o perfil que se espera desse juiz especializado? E quanto à acessibilidade a esse magistrado? De pronto, diga-se que o juiz agrário deve ser acessível e, pela característica sui generis do conflito agrário deverá sempre se deslocar ao local do fato.

De um lado estão os trabalhadores rurais, os sem terra, organizados em movimentos sociais, que agem para pressionar o governo a tomar posição de realizar e realizar a Reforma Agrária. O argumento é procedente e persuasivo, pois, fundamentados no direito de acesso a terra, previsto na Constituição Federal e legislação infraconstitucional, tal como o Estatuto da Terra. Doutro lado, os proprietários, unidos sob a argumentação da defesa e direito de propriedade, também previsto na Constituição Federal.

O conflito que decorre dessa relação social e agrária chegam às portas do Judiciário, trata-se de um fenômeno recente. O perfil do Juiz Agrário é o do 
especializado em Direito Agrário e nas questões concretas agrárias, sem olvidar os outros ramos do conhecimento, da Sociologia, Filosofia, Política, etc. Deontologicamente, o juiz é, antes de tudo, conciliador e profissional de mentalidade agrarista. Está implícita aqui a necessidade de reformulação da teleologia do ensinamento jurídico e da urgente reinserção da disciplina de Direito Agrário nos currículos das universidades. Para além dos pressupostos jurídicos, emergem os metajurídicos.

\subsection{A Competência}

O que for conteúdo do Direito Agrário é de competência da Justiça Agrária. A título exemplificativo: questões oriundas do domínio e da posse da terra rural, pública ou particular; as ações discriminatórias de terras devolutas, federais ou estaduais; as ações demarcatórias ou divisórias de imóveis rurais; as desapropriações, por interesse social, para fins de reforma agrária; as questões relativa aos negócios jurídicos agrários, compreendendo contratos agrários, financiamentos, seguros, armazenagem, transporte; os registros públicos pertinentes a imóvel rural incluindo o Registro Torrens; as questões derivadas da interferência do governo na vida rural como tributação; os delitos agrários, assim considerados os que tenham causas, objetos e/ou conseqüências predominantemente agrárias.

\subsection{Um processo agrário?}

Numa ação possessória, envolvendo o interesse coletivo de luta pela terra, não se deve ter em conta somente o direito de posse sustentado pelo autor. A ocupação se dá como ato coletivo de pressão por parte de cidadãos e cidadãs que vêem nessa forma de luta um mecanismo de conquistar condições dignas de vida, já garantidas na Constituição e não efetivadas pelo Estado.

A destarte dos empecilhos aventados é perfeitamente possível pensar na organização recursal dos tribunais agrários, observando, no que for compatível, a forma da Justiça do Trabalho, por exemplo, postulação sem advogado, bem como, presença do juízo no local do conflito. Enfím, tudo o que for necessário para instrução e realização do escopo jurisdicional. O processo agrário, nesse passo, deverá primar pela informalidade, pela publicidade, pela uniformização nos casos de situações semelhantes, pela 
oralidade e pela concentração dos atos processuais. Com simplicidade e agilidade alcançar a justiça agrária para os que dela precisam. Faz-se imperioso que os tribunais agrários sejam independentes, com juízes competentes, nomeados por concursos públicos de provas e títulos, impregnados com a mentalidade agrarista, pois, somente desta forma, pode-se alcançar o verdadeiro sentido de existir da justiça agrária.

\section{CONCLUSÃO}

Nas linhas e entrelinhas deste deparou-se com questões que, para além de uma pretensa hermenêutica neutral, exige tomada de posicionamento, atitude sui generis para esse tipo de trabalho acadêmico. Nesse passo, a proposta da Justiça Agrária ganha dimensão de mecanismo social de efetivação do princípio da função social da propriedade (da terra) e de instrumento de redução de desigualdade social.

Tratar da Questão Agrária é vindicar que se coloque na pauta-do-dia a discussão e implementação acerca do Direito fundamental do acesso a terra. Para além de um mera discussão acadêmica, está envolvido aqui a sobrevivência e a subsistência de muitos cidadãos e cidadãs, a constituírem um "patrimônio mínimo" de existir no mundo e ter reconhecido sua dignidade humana

Historicamente, quando se pensa em questão agrária no Brasil, emerge o equivalente: conflito. Juridicamente, tem emergido o equivalente: prevalência do interesse do mais forte (do latifúndio). A atualidade da temática é atestada pela presença na mídia, no imaginário popular expressado nas rodas de conversas e nos tribunais. A polêmica vem junto com a paixão causado pelo mesmo. Paixão, no melhor sentido literal: como pátere, que significa sofrimento, doença. Paixão que provoca, que mobiliza os deserdados do chão agrário, num país onde a realidade de sofrimento dos campesinos é presente.

Se o Estado é responsável pela prestação jurisdicional como forma de solucionar e dirimir conflitos, então, impõe-se como tarefa a este, em última análise, não só de exercer o jus puniendi advindo do conflito agrário, mas, sobretudo o múnus de implementar instrumentos de Acesso à Justiça, seja por meio judicial ou extrajudicial.

Assim, ao lado de uma verdadeira política de Reforma Agrária, deverse-ia conceber a possibilidade de resolução judicial das demandas advindas 
pela posse da terra, bem como de prover os órgãos com missão de pacificação social por meio de instrumentos conciliatórios, tais como a valorização da Mediação de Conflitos levada a cabo pelas Ouvidorias Agrárias que atuam no âmbito do INCRA (Instituto Nacional de Colonização e Reforma Agrária) nos Estados.

A conclusão é de que a aplicação efetiva da função social da terra se efetivará com a instituição da Justiça Agrária. Deve-se sustentar, em vias de conclusão, que o objetivo da instituição da Justiça Agrária é a efetivação de princípios elevados à condição de fundamento da República Federativa do Brasil, a saber, a dignidade da pessoa humana (CF88, art. $1^{\circ}$, III), a cidadania (CF88, art. $1^{\circ}$, II).

\section{REFERÊNCIAS}

ALFONSIN, Jacques Távora. Negros e Índios no Cativeiro da Terra. Rio de Janeiro: AJUP/FASE. 1989.

CONSTITUIÇÃO DA REPÚBLICA FEDERATIVA DO BRASIL DE 1988. Edição Especial, coordenação Emílio Sabatovski, 13ª Ed. São Paulo: Juruá, 2011.

CUNHA, Euclides da. Os Sertões. Rio de Janeiro: Ed. de Ouro, 2002.

DREIFUSS, René Armand. 1964: a conquista do Estado: ação política, poder e golpe de classe. Petrópolis, Rio de Janeiro: Vozes, 1981.

FURTADO Celso. Pequena Introdução sobre o desenvolvimento. São Paulo: Editora Nacional, 1989.

MARÉS, Carlos Frederico. Índios e Direito: O Jogo Duro do Estado. Negros e índios no Cativeiro da Terra. Rio de Janeiro: AJUP/FASE, jun 1989.

PANINI, Carmela. Reforma agrária dentro e fora da Lei: 500 anos de história inacabada. São Paulo: Paulinas, 1990. 
SANTOS, Fábio Alves dos. Direito Agrário: Política Fundiária no Brasil. Belo Horizonte: Editora Del Rey, 1995.

TOLEDO, Caio Navarro de. O Governo Goulart e o golpe de 64. São Paulo: Brasiliense, 1986.

VARELLA, M. D. Introdução ao direito à reforma agrária: o direito face aos novos conflitos sociais. São Paulo: Editora de Direito, 1998.

WARAT, Luis Alberto. Introdução Geral ao Direito II - A epistemologia jurídica da Modernidade. Porto Alegre: Sérgio Antonio Fabris Editor, 2002.

Recebido em: 2012-05-07 Aprovado para publicação em: 2012-09-18

Como citar: DE PAULA, Roberto; GARCIA, Bianco Zalmora. Varas agrárias: mecanismo de efetivação do acesso à justiça. Scientia Iuris, Londrina, v.16, n.1, p.67-82, jul.2012. DOI: $10.5433 / 2178-8189.2012$ v16n1p67. 